\title{
Mincane fındık çeşidinde klon seleksiyonu: Yağ asitleri bileşimi
}

\begin{abstract}
Ali TURAN
$\ddot{O} \mathbf{z}$

Çalışma 2014-2019 yılları arasında Trabzon ili Esiroğlu vadisinde Mincane findık çeşidinde yağ asitleri bakımından üstün özellikteki klonları belirlemek amacıyla yürütülmüştür. Araştırmanın yürütüldüğü bu vadideki farklı lokasyonlarda 14 adet Mincane klonu tespit edilmiştir. Bölgede günümüze kadar yağ asitleri bakımından değerlendirilemeyen Mincane çeşidi içerisinde büyük bir varyasyon olduğu görülmüş ve bu farklılık istatistiki olarak önemli bulunmuştur $(\mathrm{P}<0.001)$. İncelenen Mincane findık klonlarında C14:0, C16:0, C17:0, C18:0, C20:0, C22:0, C16:1, C17:1, C18:1, C20:1 ve C24:1, C18:2 ve C13:3 olmak üzere toplam 13 yağ asidi tespit edilmiş, C6:0, C8:0, C10:0, C12:0, C24:0, C22:1, C20:2 ve C22:2 toplam 8 yağ asidinin ise tespit edilebilir seviyede olmadığı saptanmıştır $(<\% 0.001)$. Çalışmada doymuş yağ asitleri \%5.78-8.18, tekli doymamış \%79.17-84.23 ve çoklu doymamış yağ asidi değerleri ise \%8.88-12.69 arasında değişkenlik göstermiştir. Bu çalışmadan elde edilen verilere göre, G13 klonu doymamış yağ asitleri bakımından ümitvar bulunmuştur. Anahtar kelimeler. Fındık, İyot değeri, Kalite index değeri, Mincane, Nervonik asit
\end{abstract}

\section{Clonal selection in Mincane (cv) hazelnuts: Fatty acids profiles}

\begin{abstract}
The aim of this work was to determine type with superior traits in terms of fatty acids profiles in Mincane cv in Esiroğlu district of Trabzon province between 2014 and 2019. In the study, 14 Mincane clones were identified in different locations in the Esiroğlu valley. It was observed that there was a large variation within the Mincane variety, which could not be evaluated in terms of fatty acids in the region until recently, and this difference was found to be statistically significant $(\mathrm{P}<0.001)$. C14:0, C16:0, C17:0, C18:0, C20:0, C22:0, C16:1, C17:1, C18:1, C20:1 and C24:1, C18:2 and C13:3 total 13 fatty acids were identified in Mincane cv, C6:0, C8:0, C10:0, C12:0, C24:0, C22:1, C20:2, and C22:2 total 8 fatty acids were not found at detectable levels $(<0.001 \%)$. In the study, saturated $5.78-8.18 \%$, monounsaturated $79.17-84.23 \%$, and polyunsaturated fatty acids varied between $8.88 \%$ and $12.69 \%$. According to the data obtained from this work, G13 clone was found to be promising in terms of its unsaturated fatty acids profiles.
\end{abstract}

Keywords: Hazelnut, Iodine value, Quality indices, Mincane, Nervonic acid

Giresun Üniversitesi, Teknik Bilimler Meslek Yüksekokulu, Bitkisel ve Hayvansal Üretim Bölümü, Fındık Eksperliği Programı, Giresun, Türkiye, ali.turan@giresun.edu.tr 


\section{Giriş}

İnsan sağlığı ve beslenmesinde önemli role sahip olan findık (Corylus avellana L.) dünyadaki en önemli sert kabuklu meyve türlerinden birisidir (Granata ve ark., 2017). Son yıllarda yapılan çalışmalar findığın, günlük diyetlerde insan vücudu için yüksek miktarda kalori, tekli ve çoklu doymamış yă̆ asitleri, vitaminler ve nutrasotikler sağladığını, bunun yanısıra zengin besin içeriğinden dolayı kalp damar hastalıkları, koroner kalp riski, tip II diyabet tedavisi, bazı kanser tedavilerinin önlenmesi ve yaşa bağlı semptomların azaltılmasını sağlayarak insan sağlığı üzerine çok önemli yararları olduğu rapor edilmiştir (Phuc ve ark., 2017; Cittadini ve ark., 2020). Bu yüzden de fındıklar yüksek miktarda yağ içermeleri nedeniyle, sağlı̆̆ destekleyici besin maddesi olarak kabul edilirler.

Organoleptik özellikleri ile de findıklar sadece bir meyve olarak değil, aynı zamanda işlenmiş gıda olarak da dünyanın her yerinde tüketilmektedir. Ayrıca findık protein, karbonhidrat, diyet lifi, vitaminler, esansiyel aminoasit, fitosteroller, antioksidan fenoller, polifenoller ve skualen içeren özel bir yă̆ bileşimine sahiptir (Sciubba ve ark., 2014; Rabadan ve ark., 2019; Krol ve ark., 2020). Diğer yandan da koroner kalp hastalığı riskini azaltan ve tansiyonu düşüren, kemik demiralizasyonunu engelleyen, önemli düzeyde mağnezyum, kalsiyum ve potasyum gibi temel mineralleri bol miktarda içermektedir (Roncero ve ark., 2016; Rabadan ve ark., 2019). Aslında findığın insan beslenmesinde temel besin maddesi olarak değerlendirilmesi, içerdiği tekli ve çoklu doymamış yağ asitlerinin varlığ (Cristofori ve ark., 2008), insanlardaki kan basıncı ve kandaki toplam kolesterolü düşürmede sahip olduğu (Torabian ve ark. 2009) önemli rolden kaynaklanmaktadır.

Fındık sadece lezzetli değil aynı zamanda kalori değeri yüksek olması nedeniyle en sevilen kuruyemişlerden bir tanesidir ve natürel ve/veya beyazlatılmış olarak tüketilmektedir. Gıda endüstrisinde fındık, kıyılmış fındık ve fındık sütü gibi bazı üst düzey ürünlerde ve kek, şekerleme ve çikolatalarda kullanılmaktadır (Fan ve ark., 2020). Yüksek kalitede doymamış yăg asidi bakımından zengin olan findık yağı, sarı renk ve lezzet bakımından yemeklik yağ olarak kullanılmaktadır (Matthaus ve ark., 2012). Yenilebilir işlevinin yanı sıra, fındık yağı sabun, kozmetik, mum vb. alanlarda da kullanılmaktadır (Alaşalvar ve ark., 2006).

Fındığın şekil ve büyüklüğü entegre tesislerin makinelerinin yapılanmasını etkilediği için işlenmesinde gerekli projelendirmeler kabuklu ve iç fındık çeşitlerinin ticari olarak tanımlanması morfolojik özellikleri olarak bilinen fiziksel özelliklere dayandırılmaktadır (Turan, 2007, Hosseinpour ve ark., 2013; Krol ve ark., 2020). Bununla birlikte, coğrafi kökenlerini göz önünde bulundurarak fındık çeşitlerinin net bir tanımını elde etmek için, genetik ve/veya metabolomik belirteçlerin kullanılması ile birlikte istatistiksel analiz yapmak daha uygun bir yöntem olarak değerlendirilmektedir (Ghisoni ve ark., 2020). 
Türkiye'de 18 standart fındık çeşidi bulunmakta ve çeşit tescil çalışmaları da devam etmektedir. Yeni tescil edilen çeşitlerin haricinde diğer çeşitlerin tamamında morfolojik özellikler bakımından büyük bir varyasyon vardır ve bu yüzden ticari olarak üretimi yapılan Tombul, Foşa ve Palaz çeşitlerinde findık üretimi yapılan bölgelerde seleksiyon başlamış ve devam etmektedir (Turan, 2021a). Ancak menşei Trabzon olan Mincane fındık çeşidinde günümüze kadar seleksiyon çalışması yapılmamıştır. Uzun yıllardır süren seleksiyon ıslahı çalışmalarına baktığımızda çok geniş alanda, çok fazla materyal ile çalışıldığı anlaşılmaktadır. Bu durumda üstün özellikli birey seçme sürecini bir taraftan uzatırken diğer taraftan da zorlaştırmaktadır. İnanılmaz potansiyeli olan Ülkemiz ve özelde Doğu Karadeniz Bölgesinde seleksiyon çalışmalarının dahi tamamlanamaması büyük bir eksiklik olarak görülmektedir. Bu eksikliğin çok hızlı bir şekilde giderilmesi ve dar alanlarda detaylı çalışma yapılması büyük önem taşımaktadır. Çünkü dar alanlarda detaylı çalışmalar yapılarak geride materyal bırakılma ve/veya hata yapma ihtimali azaltılabilmektedir.

Mincane fındık çeşidinin yetiştirildiği ve oldukça fazla varyasyona sahip Trabzon ili Esiroğlu vadisinde bu seleksiyon çalışması yürütülmüştür. Çalışma ile vadi çevresindeki tüm köy ve mahalleler detaylı taranarak üstün özellikli bireylerin seçilmesi amaçlanmıştır. Son yıllarda yapılan çalışmalarda yağ asitlerinin insan sağlığı üzerindeki olumlu etkilerinin tespit edilmesi nedeniyle bu seleksiyon çalışması yağ asitleri üzerinden yürütülmüştür. Ayrıca Esiroğlu bölgesinde tespit edilen turunçgil uzun antenli böceği (Anoplophora chinensis) zararı ve sonrasında alınan eradikasyon kararı bu çalışmanın önemini daha da arttırmıştır. Bu zararlının, Mayıs 2016'da başta Japon akçaağacı, Acer palmatum olmak üzere bazı süs bitkilerinde ciddi zararı tespit edilmiş ve bu bitkilerde önceki yıllara ait uçma deliklerinin etrafında oluşmuş odun dokusundan, bu alandaki varlığının 3-5 yıl öncesine dayanmış olabileceği öngörülmektedir (Eroğlu ve ark., 2017). Günümüze kadar yapılan survey ve arazi incelemeleri Esiroğlu vadisi civarında zararlının yayılmasının devam ettiği gözlenmiştir. Bu yüzden de her bir bahçe için kapsamlı çalışma büyük değer taşımaktadır. Çalışma sonrasında buradaki özellikle insan sağlığı bakımında üstün nitelikli bireylerin kaybolması bir yandan engellenirken diğer yandan bu bireyler findık sektörüne kazandırılarak ekonomiye ve bilime katkı sağlanacaktır.

\section{Materyal ve metot}

\subsection{Meyve örnekleri}

Çalışma 2014-2019 yılları arasında Trabzon ili Esiroğlu vadisinde yürütülmüşsür (Tablo 1). 
Tablo 1. Fındık örneklerinin lokasyonu, kodlaması, rakımı ve coğrafi pozisyonu

\begin{tabular}{lccc}
\hline Lokasyon & Klon kodu & Rakim $(\mathrm{m})$ & Coğrafi pozisyonu \\
\hline Kaynarca & $\mathrm{G} 1$ & $682 \mathrm{~m}$ & $40^{\circ} 53^{\prime} 36.0^{\prime \prime} \mathrm{N}, 39^{\circ} 39^{\prime} 06.3^{\prime \prime} \mathrm{E}$ \\
Hızarlı & $\mathrm{G} 2$ & $771 \mathrm{~m}$ & $40^{\circ} 52^{\prime} 27.50^{\prime \prime} \mathrm{N}, 39^{\circ} 39^{\prime} 45.96^{\prime \prime} \mathrm{E}$ \\
Esiroğlu & $\mathrm{G} 3$ & $205 \mathrm{~m}$ & $40^{\circ} 52^{\prime} 41.59^{\prime \prime} \mathrm{N}, 39^{\circ} 41^{\prime} 16.09^{\prime \prime} \mathrm{E}$ \\
Esiroğlu & $\mathrm{G} 4$ & $424 \mathrm{~m}$ & $40^{\circ} 52^{\prime} 50.04^{\prime \prime} \mathrm{N}, 39^{\circ} 40^{\prime} 18.62^{\prime \prime} \mathrm{E}$ \\
Hizarlı & $\mathrm{G} 5$ & $347 \mathrm{~m}$ & $40^{\circ} 51^{\prime} 35.00^{\prime \prime} \mathrm{N}, 39^{\circ} 39^{\prime} 58.15^{\prime \prime} \mathrm{E}$ \\
Gayretli & $\mathrm{G} 6$ & $280 \mathrm{~m}$ & $40^{\circ} 51^{\prime} 27.7158^{\prime \prime} \mathrm{N}, 39^{\circ} 39^{\prime} 22.8708^{\prime \prime} \mathrm{E}$ \\
Akoluk & $\mathrm{G} 7$ & $396 \mathrm{~m}$ & $40^{\circ} 55^{\prime} 05.18^{\prime \prime} \mathrm{N}, 39^{\circ} 41^{\prime} 54.11^{\prime \prime} \mathrm{E}$ \\
Barışl1 & $\mathrm{G} 8$ & $209 \mathrm{~m}$ & $40^{\circ} 52^{\prime} 15.97^{\prime \prime} \mathrm{N}, 39^{\circ} 41^{\prime} 11.04^{\prime \prime} \mathrm{E}$ \\
Hizarlı & $\mathrm{G} 9$ & $195 \mathrm{~m}$ & $40^{\circ} 52^{\prime} 11.11^{\prime \prime} \mathrm{N}, 39^{\circ} 40^{\prime} 54.43^{\prime \prime} \mathrm{E}$ \\
Barışl1 & $\mathrm{G} 10$ & $227 \mathrm{~m}$ & $40^{\circ} 52^{\prime} 37.24^{\prime \prime} \mathrm{N}, 39^{\circ} 41^{\prime} 56.89^{\prime \prime} \mathrm{E}$ \\
Yeniköy & $\mathrm{G} 11$ & $476 \mathrm{~m}$ & $40^{\circ} 51^{\prime} 13.89^{\prime \prime} \mathrm{N}, 39^{\circ} 41^{\prime} 45.72^{\prime \prime} \mathrm{E}$ \\
Barişl1 & $\mathrm{G} 12$ & $308 \mathrm{~m}$ & $40^{\circ} 52^{\prime} 09.49^{\prime \prime} \mathrm{N}, 39^{\circ} 42^{\prime} 09.58^{\prime \prime} \mathrm{E}$ \\
Günay & $\mathrm{G} 13$ & $460 \mathrm{~m}$ & $40^{\circ} 53^{\prime} 57.43^{\prime \prime} \mathrm{N}, 39^{\circ} 42^{\prime} 11.64^{\prime \prime} \mathrm{E}$ \\
Alaçam & $\mathrm{G} 14$ & $341 \mathrm{~m}$ & $40^{\circ} 52^{\prime} 56.87^{\prime \prime} \mathrm{N}, 39^{\circ} 40^{\prime} 36.52^{\prime \prime} \mathrm{E}$ \\
\hline
\end{tabular}

Seleksiyon çalışmasında bölgenin tüm köyleri incelenmiş ve büyüklüğü en az 5 da olan ve kimyasal zirai mücadele ilacı kullanılmayan 14 fındık bahçesi seçilmiştir (Şekil 1). Bu seçim işlemlerinde Tarım İlçe Müdürlüğü teknik elemanları, tarım danışmanları, muhtarlar, köylüler ve bahçe sahiplerinden bilgi ve destek alınmıştır. Çalışma seçilen bahçeyi temsil eden $\sim 25$ yaşlarındaki bir bitki (dal) üzerinde yürütülmüştür. Ayrıca bu bahçelerde çalışma süresince yılda bir defa Mart ayının ortalarında serpme şeklinde $(\sim 50 \mathrm{~kg} / \mathrm{da})$ amonyum nitrat gübresi $\left(5 \mathrm{Ca}\left(\mathrm{NO}_{3}\right) 2 \mathrm{NH}_{4} \mathrm{NO}_{3} 10 \mathrm{H}_{2} \mathrm{O}\right.$, CAN \%26N) uygulandığı, yılda iki defa dip sürgünü ve yabancı ot temizliği yapıldığı, kuruyan ve çok yaşı 1 (>50) dalların kesildiği ve başkada uygulama yapılmadığı gözlenmiştir. Seçilen bu bahçeler 5 yıl boyunca verim, hastalık ve zararlılara dayanıklılık yönünden gözlemlenmiş ve düzenli verim veren ile TGHB (2017)’ye göre hastalık ve zararlılara karşı zirai mücadele yapılması için gerekli eşik değerin altında olan bahçeler (Zararlılar: Fındık kurdu, kokarca, kozalak akarı, dalkıran; Zararlılar: Külleme ve bakteriyel yanıklık) seçilmiştir. Bu klonlardan devam eden çalışma süresince, eşik değerin üstünde hastalık ve/veya zararlı tespit edilenler elenmiş ve çalışma kalan materyal üzerinden devam etmiştir. Çalışma süresince yaklaşık 200 findık bahçesi detaylı bir şekilde incelenmiştir. Seçilen bahçelerin belirlenme, işaretleme, hasat ve kurutma işlemleri Turan ve Beyhan (2009)'a göre yapılmıştır. Kurutma sonrasında örnekler $\sim 1$ kg’lık kese kâğıdına konulmuş ve yağ ekstraksiyonu yapılana kadar $\sim 5^{\circ} \mathrm{C}$ sıcaklık ve 60--65\% nisbi nem değerinde buzdolabında muhafaza edilmiştir (Bosch KDN53NW22N A, Derin dondurucu, Almanya). 


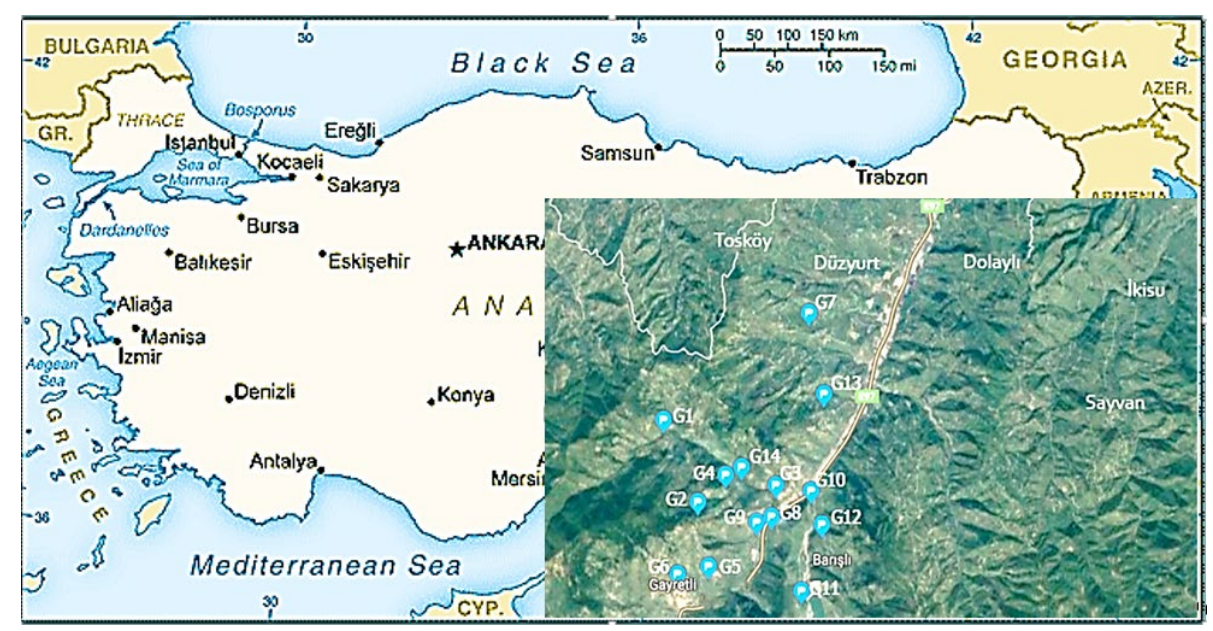

Şekil 1. Fındık klonlarının toplandığı lokasyon (Kaynak: Google Maps, ve Getamap)

\subsection{Yă̆ ekstraksiyonu}

Findık yağı Ceselsan soğuk pres yağ ekstraksiyon sistemi ile (AISI3004, Ceselsan, Giresun, Türkiye) (Basınç kuvveti: $10000 \mathrm{kgf}$, basınç: $34.7 \mathrm{MPa}$, sıcaklık:-5 ${ }^{\circ} \mathrm{C} \sim+45^{\circ} \mathrm{C}$ and kapasite; $250 \mathrm{~g}$ iç fındık) elde edilmiştir (Turan, 2018a-b). Elde edilen fındık yağı analiz yapılana kadar $-18^{\circ} \mathrm{C}$ 'de dondurucuda muhafaza edilmiştir (Bosch KDN53NW22N A, Derin dondurucu, Almanya).

\subsection{Kimyasal analizler}

Yağ asitleri analizi; yağ asitleri içeriğinin belirlenmesinde gaz kromotografisi (Shimadzu GC2010, Tokyo, Japan), yağ asidi metil esterlerinin elde edilmesinde ise Ficarra ve ark. (2010)'a küçük modifikasyon yapılarak Turan (2018a-b) ve Turan (2019)'a göre yapılmıştır. Oksidasyon parametreleri; Oleik/linoleik asit (O/L) değeri oranlama (Turan, 2018a-b), iyot değeri (IV) ise yă̆ asitleri yüzdesi (Turan, 2021b) ile hesaplanmıştır. Yağ kalite indeks değerleri; Aterojenisite (AI) ve trombojenisite indeks (TI) değerleri (Bezerra ve ark., 2017) ve hipokolesterolemik/ hiperkolesterolenik yağ asitleri oranı (H/H) değerleri Fernandes ve ark. (2019) ve Turan (2021b)'e göre yağ asitleri formülasyonu ile hesaplanmıştır.

\section{4. İstatistiksel analizler}

Seçilen klonlar üzerinde analizler üç tekerrürlü olarak yürütülmüş ve tanımlayıcı istatistikler SPSS v. 22.0 (Armok, New York: IBM Corp.)'a göre yapılmıştır. İstatistiksel testler SAS-JAMP v. 10.0 (SAS Institute Inc., Cary, North Carolina, USA) kullanılarak yapılmıştır. Sonuçlar arasındaki farkl11ık $\mathrm{P}<0.05, \mathrm{P}<0.01$ ve $\mathrm{P}<0.001$ düzeylerinde belirlenmiştir. 


\section{Bulgular ve Tartışma}

\subsection{Yağ asitleri kompozisyonu}

Mincane çeşidinde C14:0, C16:0, C17:0, C18:0, C20:0 ve C22:0 tespit edilirken, C6:0 C8:0 C10:0 C12:0 ve C24:0 doymuş yağ asitleri (SFA) tespit edilememiştir (Tablo 2). Besin olarak tüketilen doymuş yağ asitlerinin başlıca kaynakları et ve süt ürünlerinin yanı sıra bitkisel yağlardır (Hammad ve ark., 2016). Beslenmede kalp sağlı̆̆ını korumak için doymuş yağ asitleri kullanımını azaltmak gerektiği belirtilmiş (Mozaffarian ve ark., 2010) ve bu yüzden de diğer özellikler yanında SFA değeri düşük olan genotipler tercih edilmiştir. Genotipler arasında en düşük doymuş yağ asidi değeri \%6.11 ile G8'de tespit edilmişken, en yüksek değer ise \%8.18 ile G7'de tespit edilmiş ve genotipler arasındaki farklılık istatistiksel olarak önemli bulunmuştur (Tablo 2). Türk findık çeşitlerinde doymuş yağ asitleri değerinin \%5.77-8.10 arasında değiştiği (Turan, 2018a-b; Turan 2019; Turan ve İslam, 2019a-b; Turan, 2021b), Mincane çeşidinde ise bu değerin \%6.92 olduğu görülmüştür (Köksal, 2018). Doymuş yağ asidi tüketimindeki artışının kilo ve insulin direnci, anormal glisemik tepki ve yağ dokularındaki iltihap kapasitesinin artışına neden olduğu bilinmektedir (Kennedy ve ark., 2009). Bu yüzden doymuş yağ asidi tüketimi toplam enerji tüketiminin \%10'unun altında olması önerilmektedir.

Tekli doymamış yağ asitleri (MUFA) kanser ve kalp hastalıkları riskini engellemesi nedeniyle, insan sağlığı açısından hayati öneme sahiptir (Rizwan ve ark., 2019). Ayrıca MUFA tüketiminin kalp damar hastalık riskini \%20 azalttığına dair güçlü kanıtlar bulunduğunu (Gillingham ve ark., 2011) ve bu yüzden toplam enerji tüketiminin \%20'sinin MUFA olması gerektiği bildirilmektedir (Schwingshack ve ark., 2012). Çalışmada tekli doymamış yağ asitlerinden C16:1, C17:1, C18:1, C20:1 ve C24:1 tespit edilirken, C22:1 tespit edilememiştir (Tablo 2). En yüksek MUFA değeri G10 (\%84.23), en düşük değer ise G7 (\%79.17) genotipinde tespit edilmiştir.

Çoklu doymamış yağ asitlerinde (PUFA) ise C18:2 ve C13:3 tespit edilirken, C20:2 ve C22:2 yağ asitleri tespit edilememiştir (Tablo 2). Ayrıca en yüksek PUFA değeri G7 (\%12.69), en düşük ise G13 (\%9.46) genotipinde tespit edilmiştir $(\mathrm{P}<0.001)$. Bilindiği gibi PUFA insülin direncini artırarak ve sistemik iltihabı azaltarak kalp sağlı̆̆ına katkıda bulunmaktadır (Pischon ve ark., 2003). 
Tablo 2. Mincane fındık çeşidi klonlarının yağ asidi profilleri, kalite indeks değerleri ve oksidasyon parametreleri

\begin{tabular}{|c|c|c|c|c|c|c|c|c|}
\hline \multirow[b]{2}{*}{ Yap asitleri } & \multicolumn{8}{|c|}{ Klon kodu } \\
\hline & G1 & G2 & G3 & G4 & G5 & G6 & G7 & Önemlilik \\
\hline C14:0 & $0.03 \pm 0.01 \mathrm{ef}$ & $0.05 \pm 0.00 \mathrm{abc}$ & $0.05 \pm 0.01 \mathrm{bcd}$ & $0.04 \pm 0.00 \mathrm{cde}$ & $0.05 \pm 0.00 \mathrm{abc}$ & $0.05 \pm \mathrm{a} 0.00 \mathrm{bc}$ & $0.05 \pm 0.00 \mathrm{abc}$ & $* * *$ \\
\hline C16:0 & $5.63 \pm 0.01 \mathrm{~b}$ & $4.40 \pm 0.01 \mathrm{~h}$ & $3.78 \pm 0.011$ & $5.01 \pm 0.02 \mathrm{~d}$ & $4.18 \pm 0.02 \mathrm{j}$ & $5.18 \pm 0.01 \mathrm{c}$ & $5.95 \pm 0.01 \mathrm{a}$ & $* * *$ \\
\hline C18:0 & $2.13 \pm 0.01 \mathrm{c}$ & $1.80 \pm 0.02 \mathrm{~g}$ & $1.80 \pm 0.02 \mathrm{~g}$ & $2.08 \pm 0.06 \mathrm{~cd}$ & $2.11 \pm 0.03 \mathrm{c}$ & $2.73 \pm 0.02 \mathrm{a}$ & $2.00 \pm 0.07 \mathrm{de}$ & $* * *$ \\
\hline C20:0 & $0.07 \pm 0.01 b c$ & $0.08 \pm 0.00 \mathrm{abc}$ & $0.09 \pm 0.01 \mathrm{a}$ & $0.08 \pm 0.01 \mathrm{ab}$ & $0.09 \pm 0.01 \mathrm{a}$ & $0.09 \pm 0.01 \mathrm{a}$ & $0.08 \pm 0.07 \mathrm{ab}$ & $* * *$ \\
\hline $\mathrm{C} 22: 0$ & $0.04 \pm 0.01 b c$ & $0.05 \pm 0.00 \mathrm{ab}$ & $0.04 \pm 0.01 \mathrm{bc}$ & $0.05 \pm 0.00 \mathrm{ab}$ & $0.05 \pm 0.00 \mathrm{ab}$ & $0.05 \pm 0.00 \mathrm{ab}$ & $0.04 \pm 0.01 b c$ & $* * *$ \\
\hline$\Sigma$ SFA & $7.93 \pm 0.09 \mathrm{~b}$ & $6.42 \pm 0.03 \mathrm{~g}$ & $5.78 \pm 0.02 \mathrm{j}$ & $7.31 \pm 0.07 \mathrm{c}$ & $6.52 \pm 0.02 \mathrm{f}$ & $8.13 \pm 0.02 a$ & $8.18 \pm 0.06 a$ & $* * *$ \\
\hline C17:1 & $0.04 \pm 0.00 \mathrm{~b}$ & $0.05 \pm 0.01 \mathrm{ab}$ & $0.04 \pm 0.01 \mathrm{ab}$ & $0.05 \pm 0.01 \mathrm{ab}$ & $0.05 \pm 0.00 \mathrm{ab}$ & $0.05 \pm 0.00 \mathrm{ab}$ & $0.06 \pm 0.01 \mathrm{ab}$ & $*$ \\
\hline C18:1 & $80.36 \pm 0.08 \mathrm{~d}$ & $82.50 \pm 0.05 b c$ & $83.79 \pm 0.01 \mathrm{~b}$ & $80.19 \pm 0.07 \mathrm{e}$ & $81.09 \pm 0.02 \mathrm{e}$ & $79.46 \pm 0.01 \mathrm{e}$ & $78.93 \pm 0.03 f$ & $* * *$ \\
\hline C20:1 & $0.05 \pm 0.01 \mathrm{~d}$ & $0.06 \pm 0.00 \mathrm{~cd}$ & $0.06 \pm 0.00 \mathrm{~cd}$ & $0.08 \pm 0.01 \mathrm{ab}$ & $0.05 \pm 0.01 \mathrm{~d}$ & $0.05 \pm 0.01 \mathrm{~d}$ & $0.05 \pm 0.01 \mathrm{~d}$ & $* * *$ \\
\hline $\mathrm{C} 24: 1$ & $0.03 \pm 0.00 \mathrm{fg}$ & $0.06 \pm 0.00 \mathrm{bc}$ & $0.04 \pm 0.01 \mathrm{ef}$ & $0.02 \pm 0.00 \mathrm{~g}$ & $0.07 \pm 0.01 \mathrm{ab}$ & $0.07 \pm 0.01 \mathrm{ab}$ & $0.06 \pm 0.01 \mathrm{~cd}$ & $* * *$ \\
\hline$\Sigma$ MUFA & $80.57 \pm 0.09 \mathrm{~g}$ & $82.74 \pm 0.04 \mathrm{~d}$ & $84.01 \pm 0.02 b$ & $80.43 \pm 0.09 \mathrm{~h}$ & $81.35 \pm 0.02 \mathrm{f}$ & $79.74 \pm 0.02 \mathrm{j}$ & $79.17 \pm 0.04 \mathrm{k}$ & $* * *$ \\
\hline C18:2 & $11.43 \pm 0.11 \mathrm{c}$ & $10.73 \pm 0.02 \mathrm{~d}$ & $10.12 \pm 0.02 \mathrm{e}$ & $12.18 \pm 0.04 b$ & $12.04 \pm 0.05 b$ & $12.04 \pm 0.01 \mathrm{~b}$ & $12.59 \pm 0.08 \mathrm{a}$ & $* * *$ \\
\hline $\mathrm{C} 18: 3$ & $0.07 \pm 0.01 \mathrm{f}$ & $0.11 \pm 0.01 \mathrm{abc}$ & $0.09 \pm 0.01 \mathrm{c}-\mathrm{f}$ & $0.08 \pm 0.00 \mathrm{ef}$ & $0.09 \pm 0.01 \mathrm{c}-\mathrm{f}$ & $0.09 \pm 0.01 \mathrm{c}-\mathrm{f}$ & $0.10 \pm 0.00 \mathrm{a}-\mathrm{e}$ & $* * *$ \\
\hline$\Sigma$ PUFA & $11.50 \pm 0.11 \mathrm{e}$ & $10.84 \pm 0.03 \mathrm{f}$ & $10.20 \pm 0.01 \mathrm{~g}$ & $12.26 \pm 0.14 b$ & $12.13 \pm 0.02 \mathrm{c}$ & $12.13 \pm 0.02 \mathrm{c}$ & $12.69 \pm 0.03 \mathrm{a}$ & $* * *$ \\
\hline UFA/SFA & $11.61 \pm 0.06 \mathrm{i}$ & $14.57 \pm 0.07 \mathrm{~d}$ & $16.29 \pm 0.06 \mathrm{a}$ & $12.68 \pm 0.13 \mathrm{~h}$ & $14.33 \pm 0.04 \mathrm{e}$ & $11.30 \pm 0.08 \mathrm{j}$ & $11.23 \pm 0.08 \mathrm{j}$ & $* * *$ \\
\hline PUFA/SFA & $1.45 \pm 0.02 \mathrm{~g}$ & $1.69 \pm 0.01 \mathrm{~cd}$ & $1.76 \pm 0.01 b$ & $1.68 \pm 0.00 \mathrm{~cd}$ & $1.86 \pm 0.01 \mathrm{a}$ & $1.49 \pm 0.01 \mathrm{f}$ & $1.55 \pm 0.02 \mathrm{e}$ & $* * *$ \\
\hline PUFA/MUFA & $0.14 \pm 0.00 \mathrm{e}$ & $0.13 \pm 0.00 \mathrm{f}$ & $0.12 \pm 0.00 \mathrm{~g}$ & $0.15 \pm 0.00 \mathrm{c}$ & $0.15 \pm 0.00 \mathrm{~d}$ & $0.15 \pm 0.00 \mathrm{c}$ & $0.16 \pm 0.00 \mathrm{a}$ & $* * *$ \\
\hline MUFA/SFA & $10.16 \pm 0.05 \mathrm{j}$ & $12.88 \pm 0.07 \mathrm{~d}$ & $14.53 \pm 0.05 \mathrm{a}$ & $11.00 \pm 0.10 \mathrm{~h}$ & $12.47 \pm 0.03 \mathrm{e}$ & $9.80 \pm 0.03 \mathrm{k}$ & $9.68 \pm 0.07 \mathrm{k}$ & $* * *$ \\
\hline MUFA/PUFA & $7.01 \pm 0.08 \mathrm{e}^{J}$ & $7.64 \pm 0.03 \mathrm{~d}$ & $8.23 \pm 0.01 \mathrm{c}$ & $6.56 \pm 0.08 \mathrm{~g}$ & $6.71 \pm 0.01 \mathrm{f}$ & $6.57 \pm 0.01 \mathrm{~g}$ & $6.24 \pm 0.02 \mathrm{~h}$ & $* * *$ \\
\hline \multicolumn{9}{|l|}{ QI } \\
\hline AI & $0.19 \pm 0.04 \mathrm{de}$ & $0.25 \pm 0.02 \mathrm{abc}$ & $0.23 \pm 0.02 \mathrm{bcd}$ & $0.22 \pm 0.00 \mathrm{bcd}$ & $0.25 \pm 0.00 \mathrm{abc}$ & $0.26 \pm 0.00 \mathrm{ab}$ & $0.28 \pm 0.00 \mathrm{ab}$ & $* * *$ \\
\hline TI & $0.17 \pm 0.00 \mathrm{~b}$ & $0.13 \pm 0.00 \mathrm{~g}$ & $0.12 \pm 0.00 \mathrm{i}$ & $0.15 \pm 0.00 \mathrm{c}$ & $0.14 \pm 0.00 \mathrm{f}$ & $0.17 \pm 0.00 \mathrm{a}$ & $0.17 \pm 0.00 \mathrm{a}$ & $* * *$ \\
\hline $\mathrm{H} / \mathrm{H}$ & $16.23 \pm 0.13 \mathrm{k}$ & $20.98 \pm 0.05 \mathrm{e}$ & $24.54 \pm 0.06 \mathrm{a}$ & $18.30 \pm 0.09 \mathrm{i}$ & $22.02 \pm 0.08 \mathrm{c}$ & $17.53 \pm 0.02 \mathrm{j}$ & $15.26 \pm 0.021$ & $* * *$ \\
\hline \multicolumn{9}{|l|}{$\mathrm{O}$} \\
\hline $\mathrm{O} / \mathrm{L}$ & $7.03 \pm 0.07 \mathrm{e}$ & $7.69 \pm 0.02 \mathrm{~d}$ & $8.28 \pm 0.01 \mathrm{c}$ & $6.58 \pm 0.08 \mathrm{~g}$ & $6.73 \pm 0.01 \mathrm{f}$ & $6.60 \pm 0.01 \mathrm{~g}$ & $6.27 \pm 0.02 \mathrm{~h}$ & $* * *$ \\
\hline IV & $93.32 \pm 0.13 \mathrm{~h}$ & $94.05 \pm 0.05 \mathrm{f}$ & $94.08 \pm 0.02 \mathrm{ef}$ & $94.56 \pm 0.19 \mathrm{c}$ & $95.13 \pm 0.03 \mathrm{a}$ & $93.69 \pm 0.04 \mathrm{~g}$ & $94.20 \pm 0.05 \mathrm{def}$ & $* * *$ \\
\hline
\end{tabular}

SFA: Doymus yağ asitleri; C14:0; Miristik asit, C16:0; Palmitik asit, C17:0; Margarik asit, C18:0; Stearik asit, C20:0; Araşidik asit, C22:0; Behenik asit, MUFA: Tekli doymamış yağ asitleri; C16:1; Palmitoleik asit, C17:1; Heptadesenoik asit, C18:1; Oleik asit, C20:1; Eikosenoik asit, C24:1; Nervonik asit, PUFA: Çoklu doymamış yağ asitleri; C18:2; Linoleik asit, C18:3; Linolenik asit; UFA: Doymamış yağ asitleri; QI: Kalite indeks değerleri; AI: Aterojenisite, TI: Trombojenisite; H/H: Hipokolesterolemik/ hiperkolesterolenik; O: Oksidasyon parametreleri; O/L: Oleik/linoleik asit oranı; IV: İyot değeri. Ortalama \pm SD şeklinde ifade edilmiştir. Klonlar arasındaki farklılıklar farklı harflerle gösterilmiştir. Önem seviyeleri; *, **, *** ve “öd” P<0.05, 0.01, 0.001 ve “önemli değil" 
Tablo 2. Mincane fındık çeşidi klonlarının yağ asidi profilleri, kalite indeks değerleri ve oksidasyon parametreleri (Devam)

\begin{tabular}{|c|c|c|c|c|c|c|c|c|}
\hline \multirow[b]{2}{*}{ Yağ asitleri } & \multicolumn{8}{|c|}{ Klon kodu } \\
\hline & G8 & G9 & G10 & G11 & G12 & G13 & G14 & Önemlilik \\
\hline C14:0 & $0.05 \pm 0.00 \mathrm{abc}$ & $0.05 \pm 0.01 \mathrm{ab}$ & $0.04 \pm 0.01 \mathrm{def}$ & $0.04 \pm 0.01 \mathrm{def}$ & $0.04 \pm 0.01 \mathrm{def}$ & $0.03 \pm 0.01 \mathrm{f}$ & $0.06 \pm 0.00 \mathrm{a}$ & $* * *$ \\
\hline C16:0 & $3.96 \pm 0.02 \mathrm{k}$ & $4.94 \pm 0.02 \mathrm{e}$ & $4.52 \pm 0.02 \mathrm{~g}$ & $4.59 \pm 0.05 f$ & $4.95 \pm 0.03 \mathrm{e}$ & $4.31 \pm 0.02 \mathrm{i}$ & $4.32 \pm 0.01 \mathrm{i}$ & $* * *$ \\
\hline $\mathrm{C} 17: 0$ & $0.04 \pm 0.00 \mathrm{abc}$ & $0.05 \pm 0.00 \mathrm{ab}$ & $0.04 \pm 0.00 \mathrm{abc}$ & $0.05 \pm 0.01 \mathrm{ab}$ & $0.04 \pm 0.00 \mathrm{abc}$ & $0.02 \pm 0.01 \mathrm{~d}$ & $0.05 \pm 0.01 \mathrm{a}$ & $* * *$ \\
\hline C18:0 & $1.92 \pm 0.02 \mathrm{ef}$ & $1.87 \pm 0.01 \mathrm{fg}$ & $2.16 \pm 0.04 c$ & $2.59 \pm 0.01 \mathrm{~b}$ & $2.16 \pm 0.02 \mathrm{c}$ & $1.87 \pm 0.01 \mathrm{fg}$ & $1.79 \pm 0.02 \mathrm{~g}$ & $* * *$ \\
\hline C20:0 & $0.08 \pm 0.00 \mathrm{abc}$ & $0.07 \pm \mathrm{a} 0.01 \mathrm{bc}$ & $0.09 \pm 0.00 \mathrm{a}$ & $0.09 \pm 0.00 \mathrm{a}$ & $0.08 \pm 0.02 \mathrm{abc}$ & $0.06 \pm 0.01 \mathrm{c}$ & $0.07 \pm 0.01 \mathrm{bc}$ & $* * *$ \\
\hline $\mathrm{C} 22: 0$ & $0.06 \pm 0.01 \mathrm{a}$ & $0.05 \pm 0.01 \mathrm{bc}$ & $0.05 \pm 0.01 b c$ & $0.05 \pm 0.01 b c$ & $0.05 \pm 0.01 b c$ & $0.03 \pm 0.01 \mathrm{c}$ & $0.05 \pm 0.01 \mathrm{ab}$ & $* * *$ \\
\hline$\Sigma$ SFA & $6.11 \pm 0.02 \mathrm{i}$ & $7.03 \pm 0.02 \mathrm{~d}$ & $6.89 \pm 0.03 \mathrm{e}$ & $7.40 \pm 0.04 c$ & $7.31 \pm 0.04 c$ & $6.32 \pm 0.02 \mathrm{~h}$ & $6.34 \pm 0.02 \mathrm{gh}$ & $* * *$ \\
\hline C16:1 & $0.07 \pm 0.01 \mathrm{de}$ & $0.10 \pm 0.01 \mathrm{ab}$ & $0.11 \pm 0.00 \mathrm{a}$ & $0.10 \pm 0.01 \mathrm{abc}$ & $0.08 \pm 0.00 \mathrm{cde}$ & $0.07 \pm 0.01 \mathrm{de}$ & $0.08 \pm 0.00 \mathrm{cde}$ & $* * *$ \\
\hline $\mathrm{C} 17: 1$ & $0.05 \pm 0.01 \mathrm{ab}$ & $0.06 \pm 0.00 \mathrm{a}$ & $0.06 \pm 0.01 \mathrm{ab}$ & $0.05 \pm 0.01 \mathrm{ab}$ & $0.06 \pm 0.01 \mathrm{ab}$ & $0.06 \pm 0.01 \mathrm{ab}$ & $0.05 \pm 0.01 \mathrm{ab}$ & $*$ \\
\hline C18:1 & $82.79 \pm 0.02 b$ & $81.11 \pm 0.02 \mathrm{c}$ & $83.96 \pm 0.03 a$ & $79.66 \pm 0.03 \mathrm{e}$ & $80.21 \pm 0.02 \mathrm{~d}$ & $84.02 \pm 0.01 \mathrm{a}$ & $81.82 \pm 0.02 b c$ & $* * *$ \\
\hline C20:1 & $0.07 \pm 0.00 \mathrm{bc}$ & $0.06 \pm 0.01 \mathrm{~cd}$ & $0.06 \pm 0.01 \mathrm{~cd}$ & $0.09 \pm 0.01 \mathrm{a}$ & $0.09 \pm 0.01 \mathrm{a}$ & $0.03 \pm 0.01 \mathrm{e}$ & $0.05 \pm 0.00 \mathrm{~d}$ & $* * *$ \\
\hline $\mathrm{C} 24: 1$ & $0.04 \pm 0.01 \mathrm{def}$ & $0.04 \pm 0.01 \mathrm{ef}$ & $0.05 \pm 0.01 \mathrm{cde}$ & $0.09 \pm 0.01 \mathrm{a}$ & $0.03 \pm 0.00 \mathrm{fg}$ & $0.05 \pm 0.01 \mathrm{cde}$ & $0.05 \pm 0.01 \mathrm{cde}$ & $* * *$ \\
\hline$\Sigma$ MUFA & $83.02 \pm 0.01 \mathrm{c}$ & $81.37 \pm 0.03 f$ & $84.23 \pm 0.03 a$ & $79.98 \pm 0.04 \mathrm{i}$ & $80.47 \pm 0.02 \mathrm{gh}$ & $84.22 \pm 0.02 \mathrm{a}$ & $82.05 \pm 0.03 \mathrm{e}$ & $* * *$ \\
\hline C18:2 & $10.75 \pm 0.01 \mathrm{~d}$ & $11.48 \pm 0.02 \mathrm{c}$ & $8.78 \pm 0.01 \mathrm{~g}$ & $12.53 \pm 0.05 \mathrm{a}$ & $12.14 \pm 0.03 b$ & $9.37 \pm 0.02 \mathrm{f}$ & $11.51 \pm 0.02 \mathrm{c}$ & $* * *$ \\
\hline $\mathrm{C} 18: 3$ & $0.11 \pm 0.01 \mathrm{ab}$ & $0.12 \pm 0.00 \mathrm{a}$ & $0.09 \pm 0.01 \mathrm{~b}-\mathrm{e}$ & $0.10 \pm 0.01 \mathrm{~b}-\mathrm{e}$ & $0.08 \pm 0.01 \mathrm{def}$ & $0.09 \pm 0.01 \mathrm{~b}-\mathrm{e}$ & $0.10 \pm 0.01 \mathrm{a}-\mathrm{d}$ & $* * *$ \\
\hline$\Sigma$ PUFA & $10.86 \pm 0.01 \mathrm{f}$ & $11.60 \pm 0.02 \mathrm{~d}$ & $8.88 \pm 0.01 \mathrm{i}$ & $12.63 \pm 0.04 \mathrm{a}$ & $12.22 \pm 0.03 b c$ & $9.46 \pm 0.02 \mathrm{~h}$ & $11.61 \pm 0.02 \mathrm{~d}$ & $* * *$ \\
\hline UFA & $93.89 \pm 0.02 b$ & $92.97 \pm 0.02 \mathrm{~cd}$ & $93.11 \pm 0.03 \mathrm{~cd}$ & $92.61 \pm 0.04$ & $92.69 \pm 0.04 d$ & $93.68 \pm 0.02 b$ & $93.66 \pm 0.0 \mathrm{~b}$ & $* * *$ \\
\hline UFA/SFA & $15.36 \pm 0.04 b$ & $13.22 \pm 0.04 \mathrm{~g}$ & $13.51 \pm 0.06 \mathrm{f}$ & $12.52 \pm 0.07 \mathrm{~h}$ & $12.69 \pm 0.07 \mathrm{~h}$ & $14.82 \pm 0.04 \mathrm{c}$ & $14.76 \pm 0.04 c$ & $* * *$ \\
\hline PUFA/SFA & $1.78 \pm 0.01 b$ & $1.65 \pm 0.00 \mathrm{~d}$ & $1.29 \pm 0.00 \mathrm{~h}$ & $1.71 \pm 0.01 \mathrm{c}$ & $1.67 \pm 0.01 \mathrm{~cd}$ & $1.50 \pm 0.01 \mathrm{f}$ & $1.83 \pm 0.00 \mathrm{a}$ & $* * *$ \\
\hline PUFA/MUFA & $0.13 \pm 0.00 \mathrm{f}$ & $0.14 \pm 0.00 \mathrm{e}$ & $0.11 \pm 0.00 \mathrm{i}$ & $0.16 \pm 0.00 \mathrm{~b}$ & $0.15 \pm 0.00 \mathrm{c}$ & $0.11 \pm 0.00 \mathrm{~h}$ & $0.14 \pm 0.00 \mathrm{e}$ & $* * *$ \\
\hline MUFA/SFA & $13.58 \pm 0.04 b$ & $11.57 \pm 0.03 \mathrm{~g}$ & $12.23 \pm 0.05 f$ & $10.81 \pm 0.06 \mathrm{i}$ & $11.01 \pm 0.06 \mathrm{~h}$ & $13.33 \pm 0.04 c$ & $12.93 \pm 0.04 \mathrm{~d}$ & $* * *$ \\
\hline MUFA/PUFA & $7.64 \pm 0.00 \mathrm{~d}$ & $7.01 \pm 0.01 \mathrm{e}$ & $9.49 \pm 0.01 \mathrm{a}$ & $6.33 \pm 0.02 \mathrm{~h}$ & $6.59 \pm 0.02 \mathrm{~g}$ & $8.90 \pm 0.02 b$ & $7.07 \pm 0.01 \mathrm{e}$ & $* * *$ \\
\hline \multicolumn{9}{|l|}{ QI } \\
\hline AI & $0.25 \pm 0.00 \mathrm{abc}$ & $0.27 \pm 0.02 \mathrm{ab}$ & $0.20 \pm 0.02 \mathrm{cde}$ & $0.20 \pm 0.02 \mathrm{cde}$ & $0.21 \pm 0.02 \mathrm{cde}$ & $0.16 \pm 0.02 \mathrm{e}$ & $0.29 \pm 0.00 \mathrm{a}$ & $* * *$ \\
\hline TI & $0.13 \pm 0.00 \mathrm{~h}$ & $0.15 \pm 0.00 \mathrm{~d}$ & $0.14 \pm 0.00 \mathrm{e}$ & $0.16 \pm 0.00 \mathrm{c}$ & $0.15 \pm 0.00 \mathrm{c}$ & $0.13 \pm 0.00 \mathrm{~g}$ & $0.13 \pm 0.00 \mathrm{~g}$ & $* * *$ \\
\hline $\mathrm{H} / \mathrm{H}$ & $23.37 \pm 0.14 \mathrm{~b}$ & $18.57 \pm 0.06 \mathrm{~h}$ & $20.39 \pm 0.09 f$ & $19.95 \pm 0.22 \mathrm{~g}$ & $18.55 \pm 0.12 \mathrm{~h}$ & $21.57 \pm 0.06 \mathrm{~d}$ & $21.33 \pm 0.05 \mathrm{~d}$ & $* * *$ \\
\hline \multicolumn{9}{|l|}{$\mathrm{O}$} \\
\hline $\mathrm{O} / \mathrm{L}$ & $7.70 \pm 0.01 d$ & $7.06 \pm 0.01 \mathrm{e}$ & $9.56 \pm 0.02 \mathrm{a}$ & $6.36 \pm 0.02 \mathrm{~h}$ & $6.61 \pm 0.02 \mathrm{~g}$ & $8.97 \pm 0.02 b$ & $7.11 \pm 0.02 \mathrm{e}$ & $* * *$ \\
\hline IV & $94.38 \pm 0.02 \mathrm{~cd}$ & $94.27 \pm 0.01 \mathrm{de}$ & $91.88 \pm 0.02 \mathrm{j}$ & $94.80 \pm 0.06 b$ & $94.51 \pm 0.06 \mathrm{c}$ & $92.92 \pm 0.02 \mathrm{i}$ & $94.86 \pm 0.01 b$ & $* * *$ \\
\hline
\end{tabular}

SFA: Doymuş yağ asitleri; C14:0; Miristik asit, C16:0; Palmitik asit, C17:0; Margarik asit, C18:0; Stearik asit, C20:0; Araşidik asit, C22:0; Behenik asit,

MUFA: Tekli doymamış yağ asitleri; C16:1; Palmitoleik asit, C17:1; Heptadesenoik asit, C18:1; Oleik asit, C20:1; Eikosenoik asit, C24:1; Nervonik asit, PUFA: Çoklu doymamış yağ asitleri; C18:2; Linoleik asit, C18:3; Linolenik asit; UFA: Doymamış yağ asitleri; QI: Kalite indeks değerleri; AI: Aterojenisite, TI: Trombojenisite; H/H: Hipokolesterolemik/ hiperkolesterolenik; O: Oksidasyon parametreleri; O/L: Oleik/linoleik asit oranı; IV: İyot değeri Ortalama \pm SD şeklinde ifade edilmiştir. Klonlar arasındaki farklılıklar farklı harflerle gösterilmiştir. Önem seviyeleri; *, **, *** ve “öd” $\mathrm{P}<0.05,0.01,0.001$ ve "önemli değill" 
Ayrıca yüksek oranda MUFA ve PUFA değerlerinin kolesterol düşürücü özelliği yanısıra şeker hastalığı riskini azaltan glisemik indeks değerinin de düşmesine neden olduğu bilinmektedir (Esteki ve ark., 2019). Düşük oranda SFA, yüksek oranda MUFA ve PUFA değerlerini içeren findık gibi besinlerin tüketilmesi halinde kalp damar hastalığı riskinin önemli oranda azalabileceği değerlendirilmektedir (Hammad ve ark., 2016). FDA (2003) günlük 42.5 g ve EFSA (2011) ise $30 \mathrm{~g}$ iç fındık tüketmenin koroner kalp riski hastalığını azaltacağını bildirmişlerdir. Stuetz ve ark. (2017) ise bu tüketimin günlük $25 \mathrm{~g}$ olması gerektiğini bildirmişlerdir. Buradan hareketle günlük yaklaşık olarak bir avuç iç fındık tüketmenin insan sağlığı üzerine olumlu etki yapacağını ve bu etkinin doymamış yağ asitleri içeriği yüksek olan fındıkların tüketilmesi halinde daha fazla olabileceği söylenebilir.

Yağ asitleri içeriğini kültürel uygulamalar dahil pek çok faktörün etkilediği genel olarak bilinmektedir. Hasat döneminin sonuna doğru bu yağ asitleri değeri hızlı bir şekilde artış göstermektedir. O nedenle hasatta ve klon seçim aşamasında erken hasattan kesinlikle kaçınılmalı, bitki besleme ve zirai mücadele başta olmak üzere kültürel uygulamalar zamanında ve doğru bir şekilde yapılmalıdır. Çünkü iyi beslenememiş ve böcek zararına uğramış fındıklardan insan sağlığ 1 üzerine arzu edilen düzeyde katkı sağlayamayacağı önceki çalışmalarda görülmüştür (Turan, 2021b).

\subsection{Kalite indeks değerleri}

Aterojenisite (AI) ve trombojenisite (TI) indeks değerleri sıfıra yakın olması gerektiği değerlendirilmektedir (Bezerra ve ark., 2017; Turan, 2021b). Çünkü bu eğilim kalp hastalıklarını önleyen anti-aterojenik yağ asitleri seviyesinin artmasına neden olmaktadır. Bu nedenle, değerlerin sıfıra doğru yakın olması arzu edilmekte ve insan sağlığı açısından çok önemli görülmektedir. Çalışmamızda, AI ve TI değeri en düşük olarak G13 klonunda tespit edilmiştir. Bu çalışmaya dayanarak G3 klonunun kalp ve damar hastalıkları yönüyle insan sağlığına daha fazla katk1 sağlayacağından tercih edilmesinin uygun olacağı öngörülmektedir. Diğer taraftan hipokolesterolemik/hiperkolesterolenik $(\mathrm{H} / \mathrm{H})$ yăg asitleri oranı değerinin kolesterol mekanizması ile alakalı olduğu değerlendirilmekte (Turan, 2021b) ve insan sağlığı açısından yüksek olması istenmektedir. Klonlar arasında en yüksek değerler G3, G5, G8 ve G13 klonlarında kaydedilmiştir.

\subsection{Yağ oksidasyonu}

Oleik/linoleik asit oranı (O/L) değeri fındığ 1 değerlendirmede kullanılan kalite özelliklerinden birisidir ve yüksek olması arzu edilmektedir (Turan, 2018a-b; Turan ve İslam, 2018a-b; Turan, 2019; 
Turan, 2021b). Linoleik asit oleik aside göre oksidasyona karşı daha hassastır. Dolayısıyla oleik asit değerinin yüksek, linoleik asit değerinin düşük olması bu değerin yüksek olmasına, oksidasyona karşı daha kararlı olmasına neden olacaktır. Diğer taraftan da iyot değerinin (IV) yüksek olması oksidasyona karşı kararsızlık, yani hassasiyet göstergesi olarak değerlendirilmektedir (Turan, 2021b). Klonlar arasında O/L değeri en yüksek (8.97) ve iyot değeri en düşük (92.92) olarak G13, yani aynı klonda kaydedilmiştir. Elde edilen verilerden, G13 klonunun oksidasyona karşı daha dayanıklı ve dolayısıyla raf ömrünün daha uzun olduğu söylenebilir.

Yağ asitlerinin insan vücudunda bir çok işlevde hayati derecede önemli rol oynadığ genel olarak bilinmektedir (Tang ve ark., 2013). Fındıkların içerdiği yüksek orandaki tekli doymamış yağ asitleri kolesterol üzerine faydalı etkileri nedeniyle tercih edilirler (Hashempour ve ark., 2010) ve bu nedenle de sağlığı destekleyici besin olarak kabul edilirler. Diğer yandan bu yăg asitlerinin insan sağlığ1 üzerine olumlu etkisi olduğu çok sayıda çalışmada da görülmüştür (Stuetz ve ark., 2017; Piskernik ve ark., 2018; Pelvan ve ark., 2018; Wang ve ark., 2021; Comlekcioğlu ve ark., 2021, Turan, 2021b). Bu yağ asitlerinden biri olan nervonik asit (C24:1), bir yandan kandaki yağ oranını azaltma işlevi görürken diğer yandan beyin fonksiyonlarını arttırarak beyin sağlığını korumada hayati rol oynadığı son dönem çalışmalarda görülmektedir. Bu eğilim nedeniyle nervonik asit (C24:1) gıdalara eklenerek Zellwegers sendromu, andrelökodistrofi ve çoklu doku sertleşmesi gibi beyin hastalıklarının tedavisinde kullanılabilir. Ayrıca nervonik asidin dikkat eksikliği, psikoz ve şirofreni gibi hastalıkların tedavisinde kullanıldığg görülmüştür (Comlekcioğlu ve ark., 2021). Bu kadar hayati öneme sahip özelliği bakımından fındıkların günümüze kadar yeterince değerlendirilememiş olması büyük bir eksiklik olarak değerlendirilmektedir. Bu nedenle yürütülecek seleksiyon çalışmalarının özellikle II. aşamalarında fındığın insan sağlığg üzerine etkili besin içeriği konusunda değerlendirme yaparak yürütülmesinde büyük yarar görülmektedir.

Çalışma sonucunda tüm veriler bütünsel olarak değerlendirildiğinde G13 klonunun birçok özellik yönünden, özellikle de insan sağlığı üzerine muhtemel pozitif etkisi nedeniyle tercih edilmesi gerektiği ifade edilebilir. Bu güne kadar yapılan bu ve benzeri çalışmalarda pek çok genotip ile çalışılmış ve çalışmaya devam edilmektedir. Çalışmalarda tespit edilen genotiplerin çok önemli bir kısmı ümitvar görülmesine rağmen değerlendirilemediği görülmüştür (Turan, 2007). Dolayısıyla bundan sonraki çalışmalara da örnek olması bakımından amaca yönelik tek bir genotip tercih edilerek seleksiyonun ikinci aşamasına geçilecektir. Öne çıkan diğer genotiplerin bazıları da alınıp ikinci aşamada değerlendirilebilirdi. Ancak zamanı ve alanı verimli kullanmak ve amaca yönelik çalışmaları devam ettirebilmek için böyle tercihlerin arkaya takılıp kalmadan yapılmasının çok önemli olacağı düşünülmektedir. Yine de morfolojik yönden farklılıkları gözlenen ancak seçilmeyen genotiplerin genetik kaynak olarak kullanımına yönelik kayıt tutma işlemleri devam etmektedir. Genetik yapı, coğrafi farklılık, hasat zamanı, çeşit, toprak yapısı, iklim, kültürel uygulama farklılığı ve kurutma 
metodu gibi pek çok faktörün yağ asitlerinde farklılığa neden olduğu bilinen bir gerçektir (Turan, 2018a-b; Turan, 2019; Turan, 2021b). Dolayısıyla farklı arazilerde tespit edilen farkl11ıkların aynı şartlar altında değişkenlik gösterebileceği akla gelebilir. Ancak birbirine çok yakın arazi ve uygulama yöntemlerinin uygulandığı bahçeler tercih edilmiştir. Her ne kadar bazı farklılıkların test edilmesi gerektiği akla gelse de, çok uzun soluklu seleksiyon çalışması süresinde de benzer davranışları gösteren bir bireyin genetik yönden de diğerlerine göre daha üstün olabileceğini değerlendirmek yanlış olmayacaktır.

\section{Sonuç ve Öneriler}

$\mathrm{Bu}$ araştırma, Mincane fındık çeşidinde seleksiyon 1slahı konusunda ve Esiroğlu vadisinde fındıkta yapılan ilk çalışmadır. Bölgede yürütülen seleksiyon çalışmasında yă̆ asitleri bakımından çok büyük bir varyasyon olduğu görülmüştür. Buradaki farklı bireyler bu çalışma sonucunda değerlendirmeye alınmamış ancak, genetik kaynak olarak öne çıkan diğer bireyler ilgili kurum ve kuruluşlar tarafından değerlendirilmeye mutlaka alınmalıdır. Çünkü bölgede devam eden turunçgil uzun antenli böceği zararının yayılması ile bu değerli genetik kaynaklar materyali, önlem alınmazsa kaçınılmaz olarak yok olma durumu ile karşı karşıya kalacaktır.

Sonuç olarak, en düşük SFA G8, en yüksek MUFA G10 ve G13, en yüksek O/L ve en düşük iyot değeri yine G13 klonunda tespit edilmiştir. Bu yüzden, bu çalışmaya dayanarak G13 klonunun insan sağlığı için önemli olan yağ asitleri bakımından daha zengin olduğu ve diğer klonlara göre daha fazla öne çıtı̆̆g söylenebilir.

\section{Teșekkür}

Çalışma Altaş Yağ Sanayi (Ordu, Turkey) tarafından desteklenmiştir. İstatistiksel analizler için Doç. Dr. Fatih ÖNER'e teşekkür ederim.

\section{Araştırma ve Yayın Etiği Beyanı}

Yapılan çalışmada araştırma ve yayın etiğine uyulmuştur.

\section{Kaynaklar}


Bezerra, C.V., Rodrigues A.M.C., Olivera, P.D., Silva, D.A., ve Silva, L.H.M. (2017). Technological properties of amazonian oil and fats and their applications in the food industry. Food Chem, 221, 14661473.

Cittadini, M.C., Martin, D., Gallo, S., Fuente, G., Bodoira, R., Martinez, M., ve Maestri, D., (2020). Evaluation of hazelnut and walnut oil chemical traits from conventional cultivars and native genetic resources in a non-traditional crop environment from Argentina. Eur food Res Technol, 246, 833-843.

Comlekcioğlu, N ve kutlu, M., (2021). Fatty acids, bioactive substances, antioxidant and antimicrobialactivity of Ankyropetalum spp., a novel source of nervonic acid. Grasas Y Aceties, e399.

Cristofori V, Ferramondo S, Bertazza G, ve Bignami C., (2008). Nut and kernel traits and chemical composition of hazelnut (Corylus avellana L.) cultivars. J Sci Food Agric, 88, 1091-1098.

Eroğlu, M., Çoşkuner K.A., ve Usta, Y., (2017). Anoplophora chinensis (Forster, 1771) (Coleoptera: Cerambycidae) Trabzon'da; tanıtımı, gelişimi ve zararı. Kastamonu Üniv, Orman Fakültesi Dergisi, 17 (4), 565-579.

Esteki, M., Ahmadi, P., Vander Heyden, Y., ve Simal-Gandara, J., (2019). Fatty Acids-Based Quality Index to Differentiate Worldwide Commercial Pistachio Cultivars. Molecules, 24, 58.

EFSA, (2011). Scientific opinion on the substantiation of health claims related to nuts and essential fatty acids (omega-3/omega-6) in nut oil (ID 741, 1129, 1130 1305, 1407) pursuant to Article 13(1) of Regulation (EC) No 1324/2006. EFSA Journal, 9(4), 2032.

Fan, L., Ren, J., Yang, Y., ve Zhang, L., (2020). Comparative analysis on essential nutrient compositions of 23 wild Hazelnuts (Corylus heterophylla) grown in Northeast China. Journal Of Food Quality, 2020, 9.

FDA, (2003). Qualified health claims: Letter of enforcement discretion- nuts and coronary heart disease. Docket No 02P-0505. Washington DC: Food and Drug Administration.

Fernandes, I., Fernandes, T., ve Cordeiro, N., (2019). Nutritional value and fatty acid profile of two wild edible limpets from the Madeira Archipelago. Eur Food Res. Technol, 245, 895-905.

Ficarra, A., Lo Fiego, D.P., Minelli, G., ve Antonelli, A., (2010). Ultra fast analysis of subcutaneous pork fat. Food Chem, 121, 809-814.

Gillingham, L.G., Harris-Janz, S., ve Jones, P.J., (2011). Dietary monounsaturated fatty acids are protective against metabolic syndrome and cardiovascular disease risk factors. Lipids, 46(3), 209-228.

Ghisoni, S., Lucini, L., Rocchetti, G., Chiodelli, G., Farinelli, D., Tombesi, S., ve Trevisan, M., (2020). Untargeted metabolomics with multivariate analysis to discriminate hazelnut (Corylus avellana L.) cultivars and their geographical origin. $J$ Sci Food Agric, 100, 500-508.

Granata, M.U., Bracco, F., Gratani, Catoni, R., Corana, F., Mannucci, Sartori, F., ve Martino, E., (2017). Fatty acid content profile and main constituents of Corylus avellana kernel in wild type and cultivars growing in Italy. Natural Product Research, 31(2), 204-209.

GTHB, (2017). Findık entegre mücadele teknik talimatı. Gıda Tarım ve Hayvancılık Bakanlığı, Tarımsal Araştırmalar ve Politikalar Genel Müdürlüğü, Bitki Sağlığı Araştırmaları Daire Başkanlığı, Ankara.

Hammad, S., Pu, S., ve Jones, P.S., (2016). Current evidence supporting teh link dietary fatty acids and cardiovascular disease. Lipids, 51, 507-517.

Hosseinpour, A., Seifi, E., Javadi, D., Ramezanpour, S.S., Molnar, T.J., (2013). Nut and kernel characteristics of twelve hazelnut cultivars grown in Iran. Sci Hortic, 150, 410-413.

Kennedy, A., Martinez, K., Chuang, C.C., LaPoint. K., ve McIntosh. M., (2009). Saturated fatty acid-mediated inflammation and insülin resistance in adipose tissue: mechanisms of action and implications. $J$ Nutr, $139(1), 1-4$.

Köksal, A.İ., (2018). Türk findık çeşit kataloğu. Fındık Tanıtım Grubu, Ankara.

Krol, K., ve Gantner, M., (2020). Morphological traits and chemical composition of hazelnut from different geographical origins: A review. Agriculture, 10, 375.

Matthaus, B., ve Özcan, M.M. (2012). The comparison of properties of the oil and kernels of various hazelnuts from Germany and Turkey. European Journal of Lipid Science and Technology, 114(7), 801-806.

Mozaffarian, D., Micha, R., ve Wallace, S., (2010). Effects on coronary heart disease of increasing polyunsaturated fat in place of saturated fat: a systematic reviewand meta-analysis of randomized controlled trials. PLoS Med, 7(3):, e1000252.

Pelvan, E., Olun, E.Ö., Karadağ, A., ve alaşalvar, C., (2018). Phenolic profiles and antioxidant activity of Turkish Tombul hazelnut samples (natural, roasted, and roasted hazelnut skin). Food Chem, 244, 102108.

Piskernik, Vidrih, R., Demsar, L., Koron, D., Rogelj, M., Zontar, P.Z. (2018). Fatty acids profiles of seeds from different Ribes species. LWT Food Science and Technol, 98,424-427. 
Phuc, D., Popovich, D., (2017). Screening for paclitaxel and other taxanes in kernel and shell of Corylus avellana (Hazelnut). J Pharmacogn Phytochem, 6, 247-254.

Pischon, T., Hankinson, S.E., Hotamisligil, G.S., Rifai, N., Willett., W.C., ve Rimm. E.B. (2003). Habitual dietary intake of n-3 and n-6 fatty acids in relation to inflammatory markers among US men and women. Circulation, 108(2), 155-160

Rabadan, A., Alvarez-Orti, M., ve Pardo, J.E., (2019). A comparison of the effect of genotype and weather conditions on the nutritional composition of most important commercial nuts, Scientia Horticulturae, 244, 218-224.

Rizwan, S., Benincasa, C., Mehmood, K., Arjum, S., Mehmood, Z., Alizai, H.G., Azam, M.,perri, E., ve Sajjad, A., (2019). Fatty acids and phenolic profiles of extravirgin olive oils from selected italian cultivars introduced in southwestern province of Pakistan. Journal Of Oleo Science, 68(1), 33-43.

Roncero, J.M., Alvarez-Ortí, M., Pardo-Giménez, A., Gómez, R., Rabadán, A., ve Pardo, J.E., (2016). Virgin almond oil: extraction methods and composition. Grasas y Aceites, 67.

Schwingshack, L., ve Hoffmann, G., (2012) Monounsaturated fatty acids and risk of cardiovascular disease: synopsis of the evidence available from systematic reviews and meta-analyses. Nutrients, 4(12), 1989 2007.

Sciubba, F., Di Cocco, M.E., Gianferr, R., Impellizzeri, D., Mannina, L., De Salvador, F.R., Venditti, A., ve Delfini, M., 2014. Metabolic profile of different Italian cultivars of hazelnut (Corylus avellana) bynuclear magnetic resonance spectroscopy. Nat Prod Res, 28, 1075-1081.

Stuetz, W., Schlormann, W., ve Glei, M., (2017). B-vitamins, carotenoids and a-/c-tocopherol in raw and roasted nuts. Food Chem, 221, 222-227.

Torabian, S., Haddad, E., Rajara, S., Banta, J., ve Sabate, J., (2009). Acute effect of nut consumption on plasma total polyphenols, antioxidant capacity and lipid peroxidation. J Hum Nutr Diet, 22, 64-71.

Turan, A., (2007). Giresun ili Bulancak ilçesi Tombul findık klon seleksiyonu. Yüksek Lisans Tezi, Ondokuz Mayıs Üniversitesi, Fen Bilimleri Enstitüsü, Samsun.

Turan, A., ve Beyhan, N., (2009). Investigation of the pomological characteristics of selected Tombul hazelnut clones in the Bulancak area of Giresun province. Seventh International Congress on Hazelnut, Book of Proceeding (61-66), 23-27 June, Viterbo, Italy.

Turan, A., (2017). Fındıkta kurutma yöntemlerinin meyve kalitesi ve muhafazası üzerine etkileri. Doktora Tezi, Ordu Üniversitesi, Fen Bilimleri Enstitüsü, Giresun.

Turan, A., (2018a). Effect of drying methods on nut quality of hazelnuts (Corylus avellana L.). Journal of Food Science and Technology, 11, 4554-4565.

Turan, A., (2018b). Effect of drying methods on fatty acid profile and oil oxidation of hazelnut oil during storage. European Food Research and Technology, 12, 2181-2190.

Turan, A., ve İslam, A., (2019a). Tombul findık çeşidinde yağ oksidasyonunu azaltacak kurutma yönteminin belirlenmesi. GIDA,44 (4), 563-575.

Turan, A., ve İslam, A., (2019b). Hasat sonrası işlemlerin Palaz findık çeşidinin kimyasal özellikleri üzerine etkisi. I ğdır Üniversitesi Fen Bilimleri Enstitüsü Dergisi, 9(3), 1407-1416.

Turan, A., (2019). Effect of drying on the chemical composition of Çakıldak (cv) hazelnuts during storage. Grasas y Aceites, 70(1): e296.

Turan, A., (2021a, July). Evaluation of traits of selection breeding studies conducted in hazelnut. II. International Applied Statistics Conference (pp: 105-113). Tokat, Türkiye: Tokat Gaziosmanpaşa Üniversitesi.

Turan, A., (2021b). Effect of the damages caused by the green shield bug (Palomena prasina L.) on the qualitative traits of hazelnuts. Grasas Aceites 72 (1), e391.

Wang, C, Sun, Y, Zhou, Y, Cui, Y., Yao, W., Yu, H., Gou, Y., ve Xie, Y., (2021). Dynamic monitoring oxidation process of nut oils through Raman technology combined with PLSR and RF-PLSR model. LWT Food Science and Technol, 146,111290. 